Estudos RBEP

\title{
Cenas da inclusão: modelos e intervenções em experiências portuguesa e brasileira
}

Cristina Lucia Maia Coelho

\section{Resumo}

Analisa modelos de inclusão e intervenções pedagógicas nos contextos brasileiro e português, assim como o seu impacto no desenvolvimento de alunos com Necessidades Educativas Especiais (NEE). Para a realização da pesquisa, houve entrevistas com professores e consulta à legislação sobre educação especial. No Brasil, foi relatada a pesquisa Cognição em movimento, baseada nos pressupostos da avaliação interativa; em Portugal, o trabalho concentrou-se na região do Minho, dividindo-se nas temáticas Intervenção Precoce (IP), dificuldade de aprendizagem e Plano Individual de Transição (PIT). Observou-se um gap entre os modelos teóricos de inclusão e as intervenções adotadas, com variações em diferentes contextos, ainda que mantidos os princípios da política de inclusão. O acompanhamento do desenvolvimento dos alunos fez perceber uma indissociabilidade entre os sistemas microssociais e as condições macrossistêmicas.

Palavras-chave: inclusão; alunos com Necessidades Educativas Especiais; intervenção psicopedagógica. 


\section{Abstract \\ Scenes of inclusion: models and interventions in Portuguese and Brazilian experiences}

We analyze models of inclusion and educational interventions in Brazil and Portugal, as well as their impact on the development of students with special educational needs. We observed and interviewed teachers in their real school contexts, in confrontation with special education prescriptions and laws. In Brazil, we reported Cognition in Motion, research project based on the assumptions of the interactive assessment of SEN students, in a public school in Rio de Janeiro. In Portugal, the work focused on the themes of Early Intervention, Learning Difficulties and Individual Plan Transition, on the Minho region. We observed a significant gap between theoretical models, discourses of inclusion and effectively adopted interventions. Tracking pupils' development made us notice a inseparability between microsocial systems and macrosystemic conditions.

Keywords: inclusive education; children with special educational needs; interventions models.

\section{Introdução}

As políticas educacionais contemporâneas se voltam para grupos excluídos, reconhecendo os direitos sociais de sujeitos com Necessidades Educativas Especiais (NEE). A implementação da educação inclusiva - cujos contornos foram delimitados na Declaração de Salamanca, em 1994 envolve uma postura que valoriza a diversidade e as ações que favoreçam o desenvolvimento de todos os alunos (Glat, Fernandes, 2005). A política de inclusão abre um espaço de reflexão crítica sobre a história das minorias estigmatizadas e está condicionada ao redimensionamento dos projetos político-pedagógicos e à expansão da rede de apoio especializado, indo além da criação de oportunidades de acesso arquitetônico até a flexibilização curricular (Carvalho, 2004). Ainda que haja unanimidade quanto à aceitação da política de inclusão, alunos com NEE, em diversos contextos, se acham limitados a uma inserção física nas escolas regulares, enquanto sua inclusão social, afetiva e institucional permanece longe de ser alcançada (Coll, Marchesi, Palácios, 2004).

Na abordagem ecológica de Bronfenbrenner (2002), admite-se que as políticas públicas são essenciais no estudo científico do desenvolvimento humano. Nessa linha, visamos um conhecimento acerca do processo de aprendizagem que não seja dogmático, mas contextualizado, e contemple as incertezas das posturas transdisciplinares. Dessa contextualização 
emerge um pensamento complexo que se traduz como "ecologizante", situando o conhecimento em relação de inseparabilidade com seu meio cultural e sociopolítico. Compartilhamos conceito de inclusão como um processo que visa construir um ambiente apropriado a todas as crianças, adaptando programas às suas necessidades em vez de adaptar as crianças a esses programas (Kron, 2008).

Na perspectiva ecológica, o desenvolvimento está condicionado a vários níveis de sistemas (Bronfenbrenner, 2002). No microssistema, se considera o peso constitutivo que tem o papel do sujeito e suas relações (pais e agentes da escola) no desenvolvimento; quando estão em cena as interrelações entre microssistemas, fala-se do nível mesossistêmico. No nível exossistêmico, temos, por exemplo, as condições sociais dos pais de alunos. Por fim, o macrossistema se refere à cultura na qual está inserido o aluno. Neste último nível, podemos evocar a política de inclusão com valores que rompem com os limites entre ensino regular e especial.

Esses padrões de valores muitas vezes diferem entre culturas, assim como entre grupos socioeconômicos, como se vê claramente no Brasil. A concepção de transição ecológica define uma alteração no papel do sujeito no ambiente; por exemplo, um aluno que vem frequentando a sua sala regular com dificuldades e em função de avaliações passa também a frequentar outros ambientes, como a sala de recursos multifuncionais, e pode vislumbrar novas possibilidades no seu desenvolvimento. Usamos esse enfoque para esclarecer a complexidade do interjogo das forças psicológicas e culturais nos riscos ao desenvolvimento. Este trabalho analisa modelos de inclusão e intervenções pedagógicas nos contextos brasileiro e português, assim como o seu impacto no desenvolvimento de alunos com Necessidades Educativas Especiais (NEE).

\section{Método}

Realizamos observações nas escolas, entrevistamos nove professoras especializadas e consultamos a legislação relativa à educação especial. A pesquisa de campo baseou-se na perspectiva ecológica, que exige uma análise dos ambientes. No Brasil, realizamos a pesquisa Cognição em movimento, baseada nos pressupostos da avaliação interativa, em um colégio público no Rio de Janeiro. Em Portugal, o trabalho concentrou-se em cinco escolas inclusivas consideradas referência na região do Minho, localizadas em Barcelos, Ponte da Barca, Vila das Aves e Vila Praia de Âncora, dividindo-se nas temáticas Intervenção Precoce (IP), dificuldade de aprendizagem e Plano Individual de Transição (PIT).

\section{O movimento da inclusão em Portugal}

De acordo com a política educacional de Portugal, a inclusão de alunos com NEE no sistema regular de ensino se deu nas décadas de 1980 e 1990, 
influenciada pelo relatório Warnock na Inglaterra e pelo Decreto n 99-142 (Individual with Disabilities Education Act) nos Estados Unidos da América (Serrano, 2008). Assim, em Portugal cresceu o senso de responsabilidade sobre a educação de alunos com NEE por meio da publicação das Leis de Bases do Sistema Educativo. A aprovação do Decreto-Lei n 319/23, de 1991, deu à escola o suporte legal para o atendimento das crianças com NEE e introduziu princípios de integração.

Na definição de Necessidades Educativas Especiais - de acordo com os princípios das resoluções de entidades como a Organização das Nações Unidas para a Educação, a Ciência e a Cultura (Unesco), a Organização para Cooperação e Desenvolvimento Econômico (OCDE) e a Comunidade Econômica Europeia (CEE) -, foram substituídos os critérios médicos pelos pedagógicos. O conceito de NEE reflete uma filosofia de integração e igualdade de direitos com bases não discriminatórias quanto a raça, religião, características físicas e intelectuais, de acordo com a Declaração Mundial de Educação para Todos, de 1990. No Diploma 995/95 são estabelecidas verbas especiais para escolas inclusivas e apoio social às famílias. De início, houve a integração física dos alunos com NEE nas escolas, e, em seguida, as integrações social e acadêmica foram reforçadas.

Com a evolução do movimento, a educação especial deixou de ser um "lugar" e passou a ser considerada um serviço de apoio especializado - acadêmico, psicológico, social e clínico -, destinado a responder às necessidades especiais dos alunos, a fim de maximizar o seu potencial (Correia, 2008a). Deve ter como objetivo a prevenção, redução ou supressão da problemática do aluno, seja ela de foro mental, físico ou emocional, ou a modificação de ambientes de aprendizagem, visando uma educação apropriada às suas capacidades. Nesse contexto, um modelo foi desenvolvido por Correia (2008a), designado Escola Contemporânea, na qual o aluno é visto considerando-se três níveis de desenvolvimento: acadêmico, socioemocional e pessoal. Nesse paradigma, o Estado se responsabiliza pela sensibilização do público e por medidas legislativas, enquanto a escola se volta para a flexibilização dos currículos e das práticas, considerando os ritmos de aprendizagem e de desenvolvimento dos alunos. Em um cenário de diversidade, a educação inclusiva envolve crianças em risco educacional e as com necessidades especiais e com sobredotação.

Correia (2008a) chama a atenção para a necessidade de superação dos discursos dominantes na compreensão dos alunos com NEE, como o caritativo, o laico, o normativo, que evidencia os direitos legais dos alunos, e o discurso clínico ou psicopedagógico, que frisa as avaliações psicológicas. Refere-se ainda ao discurso social, que apela para os direitos dos alunos, e, por fim, ressalta o discurso educacional, que refletiria uma interseção entre o legislativo, o psicopedagógico e o social. O discurso educacional levou o autor a conceber um Modelo de Atendimento à Diversidade (MAD), que supõe que se cada aluno receber precocemente uma intervenção terá poucas possibilidades de precisar dos serviços de educação especial. O modelo prevê ajustes, caso o aluno não apresente 
respostas ao currículo regular. Nessa perspectiva, a ausência de uma intervenção adequada pode levar um aluno inteligente ao fracasso, o que retrataria a incapacidade dos professores. O modelo é constituído por níveis - conhecimento, planificação e intervenção -, devendo cada um ser reavaliado através de uma verificação: o conhecimento do aluno e de seus ambientes de aprendizagem determina seus níveis de realização acadêmica e social; a planificação envolve a análise das informações; por fim, a intervenção, que supõe um carácter preventivo, reeducativo e transicional, se baseia na observação contínua dos progressos dos alunos ante as estratégias. O componente reeducativo apoia-se na avaliação compreensiva, traçando o perfil do aluno com base no seu funcionamento global e a elaboração de Planos Educativos Individualizados (PEI), baseados em aspectos de cognição, adaptabilidade e seu aproveitamento. A partir dessas informações, poder-se-á determinar a elegibilidade do aluno para a educação especial. O componente transicional é dirigido a alunos que não atingiram os objetivos do currículo comum e, devido à idade avançada, necessitam de medidas visando a sua inserção na sociedade e no mundo laboral.

Ainda que a prevalência internacional seja de $12 \%$, a política do Ministério da Educação para alunos com NEE se baseia no argumento de que 1,8\% dos estudantes precisariam dos serviços. Para Serrano (2008), a visão reducionista é associada a medidas econômicas que não protegem os direitos do aluno com NEE. A autora destacou aspectos positivos do Decreto-Lei no 319/23, a saber: a) os Planos Educativos Individual de Transição; b) a confidencialidade no atendimento; e c) os departamentos de educação especial nas escolas. Como pontos fracos ressaltou a necessidade de acesso a todos os alunos com NEE - não apenas deficientes físicos, mentais/sensoriais e múltiplas desordens - e o uso obrigatório da Classificação Internacional de Funcionalidade, Incapacidade e Saúde (CIF), Decreto-Lei $n^{\circ}$ 3/2008, para determinar a elegibilidade do aluno com NEE. Segundo a autora, o uso da CIF não deveria ser obrigatório até que pesquisas mostrassem sua utilidade. A CIF constitui uma referência universal adotada pela Organização Mundial da Saúde (OMS) para avaliar a saúde e a incapacidade em nível tanto individual quanto da população e divide-se em três componentes, a saber: um corporal, um relacionado a atividade e participação e outro a fatores ambientais. Segundo Correia e Lavrador (2010), o decreto foi interpretado como uma imposição, devido à falta de consulta a investigadores. Ainda que a CIF esteja caracterizada como "uma ferramenta científica e internacional para a mudança de paradigma de um modelo médico para um modelo biopsicossocial e integrado", um dos erros indicados pelo autor seria o de obrigar o seu uso para a elaboração do Programa Educativo Individualizado (PEI). Um estudo apontou para a falta de formação (na CIF) da maioria dos profissionais (Correia, Lavrador, 2010), e muitos deles revelaram que nunca haviam utilizado o instrumento. Uma contradição é apontada quando os participantes admitiam que a CIF fosse eficaz, mas, ao mesmo tempo, insuficiente para a elaboração do PEI. Quando solicitados a analisar um 
caso, encontraram-se heterogeneidade de posições entre os participantes, indicando inexperiência e divergências na interpretação e na avaliação. Segundo Correia e Lavrador (2010), "ela pode sinalizar problemas de foro físico, mas não abarca problemas acadêmicos e emocionais necessários para a elaboração de PEI de alunos com Dificuldade de Aprendizagem Específica (DAE) e problemas de comportamento, que constituem 60\% dos casos".

Cumprimos a lei, mas a CIF não nos é útil. Na nossa avaliação, os alunos são observados pelos professores, que identificam algo aquém dos padrões normais. Através de uma avaliação compreensiva, levantamos a história de vida do aluno, incluindo a entrevista com os pais, para fazermos o encaminhamento. (Rosa Maria Ferreira, coordenadora de educação especial da escola de Vila Praia de Âncora)

\section{A inclusão e a Intervenção Precoce em Portugal}

Intervenção Precoce (IP) pode ser concebida como ciência e como prática terapêutica envolvendo serviços prestados a crianças em risco ou com NEE, com idades entre 0 e 6 anos, em contextos naturais, de forma integrada, interdisciplinar e centrada na família, com o objetivo de potencializar o seu desenvolvimento (Correia, Serrano, 2008). A educação infantil tem sido prioridade da Comissão de Educação da OCDE, reforçando os alicerces da aprendizagem ao longo da vida. O projeto Educação de Infância em Contextos Inclusivos (Eceis), envolvendo países como Alemanha, Portugal, França, Hungria e Suécia, é um exemplo dessa tendência (Serrano, Afonso, 2010).

Em Portugal adota-se a abordagem centrada na família, reconhecendo que as famílias são o contexto principal para o desenvolvimento da criança, enfatizando as competências da criança e da família, assim como a parceria família-profissional. Para implementação do modelo faz-se necessária a formação específica em Intervenção Precoce (IP), políticas públicas uniformizando o funcionamento das equipes e a estabilidade no vínculo contratual dos profissionais. Numa perspectiva social e multifacetada, IP é a prestação de apoio informal e formal a famílias por redes sociais, que influenciam direta e indiretamente o desenvolvimento da criança. A rede social (comunitária ou intrafamiliar) fornece apoio necessário à vida do dia a dia, ao cumprimento das responsabilidades parentais, à aprendizagem e ao desenvolvimento da criança. Os serviços de apoio às crianças de 0 a 3 anos dependem do Ministério da Solidariedade e da Segurança Social, ${ }^{1}$ além de entidades como cooperativas e instituições privadas. Os Ministérios da Educação e da Solidariedade e da Segurança Social são responsáveis pela educação pré-escolar (3 a 6 anos), pelo apoio às famílias e pela definição de regras quanto aos aspectos pedagógicos. De acordo com o Decreto-Lei n ${ }^{\circ}$ 319/91, os pais - participantes na elaboração dos PEI - têm o direito de decidir sobre a educação de seu filho e de expressar seus sentimentos e ideias sobre a avaliação, além de garantias quanto ao aspecto confidencial das informações sobre seu filho. Em 1997,
${ }^{1}$ Com a entrada em funções do XIX Governo Constitucional (D.L. no 86-A/20011, de 12 de julho), foi extinto o Ministério do Trabalho e da Solidariedade Social e criado o Ministério da Solidariedade e da Segurança Social, transitando as áreas do trabalho, emprego e formação profissional para o Ministério da Economia e do Emprego. 
o Ministério da Educação (Portaria n 52) reconheceu a necessidade de programas de IP (Serrano, 2008), e o Despacho Conjunto no 891/99 a regularizou, estabelecendo que:

1) o público-alvo é de crianças de alto risco ou com necessidades especiais e suas famílias;

2) as intervenções não se limitam à educação, têm foco na família e são de responsabilidade dos Ministérios da Saúde, da Educação e do Bem-Estar Social;

3) a implementação é assegurada por uma equipe transdisciplinar.

\section{Condições de risco, IP e apoio social}

Fatores de risco se referem a uma condição de probabilidade do aparecimento de problemas no desenvolvimento e impõem medidas de precaução. A combinação de fatores coloca a criança em uma situação de risco substancialmente aumentada quanto ao comprometimento do seu desenvolvimento. Os riscos podem ser:

a) Estabelecidos - um quadro patológico, como anomalias congênitas.

b) Biológicos - situações potencialmente lesivas ao desenvolvimento, como crianças prematuras ou filhos de toxicodependentes.

c) Ambientais - presença de fatores sociais prejudiciais, como crianças que sofreram abusos (Meisels, Anastasiow, 1982).

No enfrentamento dos fatores de risco, a IP representa uma ação preventiva ao uso da educação especial. A investigação tem produzido uma compreensão sobre sua natureza multidimensional e da complexidade do impacto das relações de apoio nas famílias (Dunst, 1985). Apoio social envolve trocas complexas de recursos entre as famílias, os membros das suas redes sociais e os profissionais. A ajuda de caráter emocional, informativo ou instrumental prestada pelas redes influencia a saúde, a adaptação aos acontecimentos da vida e o desenvolvimento do receptor de tal ajuda. As redes formais são representativas das instituições de saúde, educação, segurança social e justiça, e as informais referem-se a amigos, família alargada, grupos sociais e comunidades. No modelo de corresponsabilização, a IP contempla a influência dos membros da família no sentido de capacitá-los na procura de recursos que satisfaçam suas necessidades (Dunst, Trivette, Deal, 1998). Considerando o desenvolvimento da criança a partir de estimulações nos seus contextos de vida, McWilliam (2000) alerta-nos para a valorização da família e da comunidade enquanto ambientes naturais de aprendizagem. O apoio aos pais quanto às suas responsabilidades incluem informações que tanto fortalecem as competências já existentes como promovem novas outras que potencializam o desenvolvimento da criança (Dunst, Bruder, 1999). 
Um estudo sobre IP identificou que o item descritor do tipo de assistência assinalado como ajuda muito ${ }^{2}$ acontecia com maior frequência nas redes informais (Serrano, 2008). Os casos em que o ajuda muito acontecia com maior frequência nas redes formais eram em famílias com filhos com problemas severos ou em condições de pobreza. O tipo de apoio providenciado pelas redes informais diferia do das redes formais. A informação e o apoio material aparecem mais nas redes formais, enquanto os apoios emocional e instrumental e a redução do stress aparecem mais nas redes informais. Vale registrar que as diretrizes da lei são baseadas nos princípios da Division for Early Childhood do Council for Exceptional Children (DEC) (Serrano, 2008), a saber:

1) Avaliação da criança no seu contexto cultural de forma singularizada;

2) As intervenções visam a segurança, a aprendizagem e a participação da criança;

3) Práticas flexíveis baseadas na responsabilidade das famílias e de equipes interdisciplinares.

A abordagem centrada na família ressalta a dignidade e o respeito a suas decisões e a sensibilidade dos profissionais à diversidade sociocultural e prioridades e regras das famílias.

Segundo uma especialista em IP, ainda que não tenha realizado o curso de formação na CIF, ela a utiliza baseada na sua experiência e nem sempre conta com uma equipe multidisciplinar. De início é feita a referenciação pelos pais ou professores, através de formulários que são submetidos à avaliação, e, posteriormente, uma visita às famílias e a observação da criança. Após o diagnóstico, o profissional decide sobre a elegibilidade da criança:

\footnotetext{
Uma vez elegível, a partir do relatório técnico-pedagógico, elabora-se o PEI e o programa de intervenção do aluno. O meu agrupamento apoia as instituições privadas, considerando-se que nas públicas há professores de educação especial. É de responsabilidade do Ministério da Educação fornecer especialistas em IP, equipe ligada à saúde e à ação social. (Ana Isabel Oliveira, jardim da infância Casa do Menino Deus, especialista em IP, mestranda em educação especial na UMinho)
}

Em uma turma do jardim da infância na Casa do Menino Deus havia dois alunos com NEE, um deles com uma síndrome cromossômica e outro com glaucoma. No seu relato, a professora, com 18 anos de experiência, admite que "a inclusão é gratificante", e acrescenta que o apoio aos alunos é integrado ao projeto da escola em atividades coletivas, contando para tanto com a especialista em IP e uma auxiliar de ação educativa. Especificamente no caso do aluno Marcelo - com deficiências físicas, intelectuais e atentivas -, os objetivos do PEI envolviam competências como autonomia, expressão da linguagem oral, socialização e integração.
2 Os itens eram: "ajuda muito", "ajuda", "causa stress". 
${ }^{3}$ O Jardim da Infância Casa do Menino Deus recebeu o Certificado Nacional de Qualidade, que avalia critérios como espaço físico e o trabalho pedagógico.
A autonomia se refere a comportamentos como fazer as refeições com independência. Visamos o aumento do seu potencial de comunicação, já que ele tem a linguagem compreensiva, mas não se expressa. É frustrante não conseguirmos compreendê-lo. A professora de IP o entende. A solidariedade das crianças o ajuda. Costumava se isolar, hoje já chega ao grupo. Já tivemos uma vitória, pois ele não se submetia às rotinas. Era conhecido como a "borboletinha", não sentava um minuto. Hoje ele já fica nas minhas pernas. (Conceição Sá, Licenciada em educação da infância. Jardim da Infância Casa do Menino Deus, Barcelos)

Quanto à aluna com glaucoma, considerando sua fotofobia, os cuidados envolviam mantê-la sempre de costas para a janela. A inclusão promove a sensibilização e a conscientização dos membros de uma determinada comunidade, porque permite uma maior visibilidade das crianças com NEE. Assim, a comunidade escolar percebe essas crianças como parte de um todo, e tanto as com NEE quanto as que não as têm se beneficiam nos domínios da socialização e da cognição. Consideremos as palavras da professora do Jardim de Infância: ${ }^{3}$

Nosso objetivo é o desenvolvimento integral das crianças, levando em
conta aspectos morais, sociais e cognitivos. A inclusão para mim é
natural, pois nunca estive em contextos não inclusivos. Um avanço que
numa criança normal seria desapercebido, para esta torna-se um grande
avanço, mexendo com a autoestima dos pais. A evolução do Marcelo se
dá em nível de socialização. Em nível de autonomia já temos ganhos,
pois já come sozinho e tenta calçar as meias. (entrevista realizada
em 04/2011 e a anterior, em 11/2010). (Conceição Sá, licenciada em
educação da infância. Jardim da Infância Casa do Menino Deus, em
Barcelos)

A partir das observações no Jardim Casa do Menino Deus, constatou-se um ambiente de aprendizagem que favorecia a todos num contexto de diversidade. As práticas aconteciam com participação da turma e apoio dos auxiliares no processo educativo. Havia o espaço do grafismo com arte, da biblioteca, da pintura, do alfabeto, da cozinha, das regras, além da área externa e do refeitório, onde todos participavam de diferentes experiências. Na abordagem ecológica, a capacidade de os ambientes intensificarem o desenvolvimento intelectual e educacional depende de como o pessoal da escola, em suas interações com a criança, encoraje atividades orientadas para tarefa. "O potencial desenvolvimental de um ambiente depende da extensão em que os agentes da escola criam oportunidades para a criança se envolver em atividades interpessoais progressivamente mais complexas" (Bronfenbrenner, 2002, p. 35).

Na escola de Vila Praia de Âncora é desenvolvido um trabalho de caráter preventivo de acordo com o Modelo de Atendimento à Diversidade (MAD) (Correia, 2008a). Para tanto, as professoras de educação especial, em contato com jardins da infância do distrito, identificam os problemas das crianças que irão se matricular na escola no próximo período, visando orientar as educadoras na elaboração do plano individualizado. A ideia era a de que quanto mais precoce fosse a intervenção menor seria a probabilidade de o aluno vir a precisar de educação especial. "Um dos 
alunos está em terapia da fala, e já contatamos a terapeuta, visando planejarmos os objetivos de acordo com as suas necessidades." (Prof ${ }^{a}$. Rosa Maria Ferreira, coordenadora de educação especial da escola de Vila Praia de Âncora).

Segundo a coordenadora, a legislação nem sempre é cumprida: "Aí entra a questão da política educativa de Portugal. A IP só existe a partir dos três anos, quando deveria existir desde o nascimento". Para a professora, o quadro de educação especial é inadequado, pois o Ministério considera todos técnicos de educação, permitindo que professores sem formação especializada atuem na educação infantil, enquanto os especializados podem lecionar até no $3^{\circ}$ ciclo.

Nesta escola, as educadoras da infância são responsáveis apenas pelo jardim. Já tivemos IP no país, com protocolos com Centros de Saúde que não existem mais por razões econômicas. Muitos alunos se tivessem tido IP nem precisariam de educação especial. O que previmos é que daqui a 3 ou 4 anos vão chegar no $1^{\circ}$ ano crianças que não conhecemos, com problemas. Quanto mais precoce for a intervenção melhor, não apenas o apoio educativo. (Rosa Maria Ferreira, coordenadora de educação especial da escola de Vila Praia de Âncora)

Ainda que sejam gratuitos, os serviços nacionais de saúde para recém-nascidos de alto-risco parecem desarticulados das ações de outros ministérios. O programa "Ser Criança", do Ministério da Segurança Social (Despacho no 26/95, Portaria $n^{\circ} 1.102 / 97$ ), encoraja as instituições privadas a desenvolverem programas para menores de três anos. "Os programas sociais, de saúde, educativos e de justiça do ponto de vista organizacional não são articulados, resultando em uma prestação fragmentada de serviços" (Serrano, 2008, p. 70). Um exemplo que foge a esta lógica da fragmentação refere-se ao "Projeto Integrado de Intervenção Precoce de Coimbra", de 1989 - baseado na perspectiva ecológica -, que apoiava famílias de crianças com NEE. Esse programa, integrado e multidisciplinar, foi precursor do atual Sistema Nacional de Intervenção Precoce na Infância (SNIPI) (Decreto-Lei 281/09), coordenado pelos Ministérios do Trabalho e da Solidariedade Social, da Saúde e da Educação, coordenações regionais e equipes multidisciplinares (Serrano, 2008). O SNIPI integra-se na Convenção das Nações Unidas dos Direitos da Criança e no Plano de Ação para a Integração das Pessoas com Deficiências (2006-2009) e tem como missão garantir o desenvolvimento das crianças com limitações funcionais, físicas, ou com grave risco no desenvolvimento, com o envolvimento das famílias e da comunidade.

\section{A inclusão, Dificuldade de Aprendizagem Específica (DAE) e defi- ciências}

Em Portugal, alunos com dificuldades de aprendizagem não são elegíveis para os serviços de educação especial, com exceção de casos considerados muito graves. 
É previsto um apoio educativo, mas é insuficiente, pois este tipo de aluno precisa de um especialista. É preciso fazer a distinção entre DAE e as deficiências mentais leves e moderadas, o que é muito difícil, principalmente em alunos mais velhos. (Rosa Maria Ferreira, coordenadora de educação especial da escola de Vila Praia de Âncora)

Como os alunos com DAE correspondem a cerca de $48 \%$ dos casos, os recursos necessários são muito altos. Assim, além da necessidade de especialistas, se impõe o investimento na formação de base e continuada de educadores, incluindo a disciplina DAE nos currículos. A professora ressaltou que nem sempre há professores para ministrá-la:

\begin{abstract}
Estes cursos só existem na Universidade do Minho, cujo Mestrado em Educação Especial prevê as áreas de Dificuldade de Aprendizagem e Intervenção Precoce. Sem este investimento, estamos a atirar alunos inteligentes ao insucesso. Recebemos crianças com 11 e 12 anos sem saber ler, escrever, mas que a partir de intervenções especializadas conseguimos fazê-las ler. Mas não tenhamos ilusões, o tempo passou e muito deixou de ser feito. O problema não se deve à incapacidade do aluno, mas aos professores que não foram preparados. (Rosa Maria Ferreira, coordenadora de educação especial da escola de Vila Praia de Âncora)
\end{abstract}

Segundo estudo realizado com profissionais das áreas da saúde e educação, concluiu-se ser consensual que a identificação dos alunos com DAE deva ter uma perspectiva clínica. Os profissionais admitem como desafios: formação, conceitos definidos, apoio às escolas, investigação, produção de instrumentos de avaliação, programas de intervenção e conscientização social e política. Numa definição proposta por Correia (2008b), o grupo de alunos com DAE é caracterizado por ser heterogêneo e não apresentar deficiência mental nem transtornos do desenvolvimento. O critério de identificação da DAE refere-se à discrepância entre o coeficiente de inteligência - que nestes casos é de nível médio a alto - e o baixo rendimento acadêmico. Neste grupo estão incluídos os casos neurológicos, como os de Transtorno do Déficit de Atenção com Hiperatividade (TDAH) e Dislexia. Na pesquisa, conclui-se os seguintes pontos:

1) a necessidade da prevenção;

2) não existe uma compreensão sobre o que seja uma educação especial de qualidade;

3) a supremacia dos aspectos teóricos/científicos sobre os politicos/ educacionais;

4) o termo DAE é utilizado de uma forma polissêmica.

Visando práticas educativas eficazes, o autor assinala a necessidade de uma relação de equilíbrio entre o científico, o social e o político na definição de DAE, assim como a substituição do modelo clínico por um modelo educacional.

Temos alunos com dislexia diagnosticados com deficiência mental precocemente, mas que fazem aprendizagens no contexto normal da turma, com ajuda da professora de educação especial. Na disciplina 
de história, por exemplo, a avaliação é a mesma da turma, com adaptações na leitura na situação de teste. O que importa, neste caso, é a compreensão do conteúdo. (Rosa Maria Ferreira, coordenadora de educação especial da escola de Vila Praia de Âncora)

Nas intervenções com alunos disléxicos, a professora considerou fundamental o estímulo ao pensamento das crianças para ultrapassar as dificuldades, assim como o uso de exercícios de reeducação - velocidade da leitura, ortografia e expansão da escrita, porém, sem padronização. Mesmo sem amparo na legislação, alunos com DAE são submetidos a intervenções por iniciativa da coordenação de educação especial. Fica evidenciado que as estratégias de aprendizagem se focam no trabalho remetido a um conteúdo e não ao uso vazio de palavras. Na orquestra de flauta, encontramos Jade, de 11 anos. Diz a professora: "Aqui os meninos estão totalmente incluídos. A Jade veio para esta escola no ano passado." E pergunta à própria aluna: "O que você sabia?" Ao que ela respondeu: "Nada!" A professora continua: "Ela não conhecia o alfabeto e no momento está quase ao nível da turma, desenvolvendo suas capacidades que só estavam adormecidas." (Rosa Maria Ferreira, coordenadora de educação especial da escola de Vila Praia de Âncora).

A professora Berta - coordenadora de ensino especial do Concelho de Barcellos - apoia a legislação ao concordar que os casos de DAE não sejam necessariamente incluídos na educação especial, destacando que, para tanto, é preciso ter rigor. Ressaltou que, em Portugal, por muito tempo, alunos com desenvolvimento lento podiam ser considerados deficientes. Aproveitavam-se da lei como pretexto para reduzir turmas e solicitar professores de apoio. Nesse período, as avaliações deixavam de se basear em critérios médico/clínicos para serem unicamente pedagógicos. O Decreto ${ }^{\circ}$ 3/2008 determinou que as equipes são obrigadas a avaliar pela CIF. Com formação na CIF, a professora apoia seu uso, mas destacou que nem todos da equipe - que deve ser multidisciplinar - têm o curso exigido pelo Ministério da Educação e admitiu que o trabalho se torna difícil com professores sem o curso, na medida em que a equipe deve chegar a um critério de elegibilidade do aluno, acrescentando que é difícil distinguir uma criança com DAE num limiar grave daquelas com dificuldades no raciocínio abstrato.

Temos meninos no código 3 da CIF - educação especial - sem deficiência visível. Fazer um relatório sobre o perfil de funcionalidade do aluno nos aspectos pedagógicos e clínicos depende do bom senso. Não concordo que a CIF identifique apenas deficientes. Muitos não têm deficiência, mas têm pouca funcionalidade e fazem jus à educação especial. São comuns perguntas no site do Ministério, como: "o aluno com TDAH entra na educação especial?" A rigor não, depende do nível de funcionalidade do aluno. (Berta, coordenadora de ensino especial do Concelho de Barcellos)

A professora admitiu que muitos consideravam alunos com problemas de leitura e escrita como disléxicos. Essa questão traz à tona o que é primário e o que é secundário no diagnóstico. São raros os disléxicos 
puros e, nestes casos, a dislexia pode não ser o foco principal. Por exemplo, portadores de Síndrome de Down têm problemas de expressão verbal, porém, ressaltou, este não é o fator primário. Acrescentou que muitos estão debruçados na problemática se os alunos precisam ou não de terapia da fala, quando deveriam estar investindo na aprendizagem significativa. Para a professora, é comum se referenciarem alunos para terapia da fala desnecessariamente: "Na verdade, o que eles precisam não é necessariamente falar corretamente, mas desenvolver a linguagem em contexto, interagir e se comunicar." Destacou o conceito de aprendizagem em contexto: "Um tratamento específico na linguagem não vai acrescentar nada na avaliação, mas sim um contexto pedagógico rico." Ao valorizar a presença dos alunos com NEE nas salas regulares, a professora Berta questiona a presença do professor de apoio na sala regular: "Muitas vezes o professor de apoio faz um trabalho demasiadamente particularizado e desarticulado com o tema desenvolvido pelo professor da turma." Destacou que os alunos se identificam com a professora da turma regular, pois é sua referência no grupo; para ela, ao retirarmos aluno do contexto da sala de aula regular lhe retiramos oportunidades de aprendizagem e o condicionamos ao apoio individualizado: "Alunos com problemas de comportamento são mais complicados para a professora dar conta sozinha, mas com os alunos com problemas cognitivos temos exemplos positivos." (Berta, coordenadora de ensino especial de Barcellos). Nas intervenções, destacavam-se os níveis de realização, estilos de aprendizagem e o uso de estratégias específicas:

Temos uma aluna com 11 anos - que não lia nem escrevia - com o diagnóstico de deficiência mental. Supostamente seria uma avaliação segura, considerando sua idade sem ter sido alfabetizada, e não era. Ela tinha dificuldades de aprendizagens severas e, com intervenções, hoje está alfabetizada. (Rosa Maria Ferreira, coordenadora de educação especial da escola de Vila Praia de Âncora)

\begin{abstract}
Já tivemos um aluno de 12 anos que não escrevia nem lia e foi fazendo aprendizagens graduais ao longo de dois anos. Precisamos de tempo para consolidar as aprendizagens. Se realizada num momento mais precoce, a avaliação psicológica é mais significativa. Com crianças mais velhas o atraso escolar é tanto que duvidamos se é dificuldade de aprendizagem ou outro distúrbio. Com tantos anos sem experiências de aprendizagem provavelmente irá fracassar nos testes de inteligência. (Rosa Maria Ferreira, coordenadora de educação especial da escola de Vila Praia de Âncora)
\end{abstract}

Para as professoras, há uma evidente determinação de problemas socioeconômicos na construção das deficiências, sendo algumas, na verdade, pseudodeficiências. Considerou-se que há muita desresponsabilização por parte das famílias que deixam de enviar os filhos à escola, e as crianças vão construindo um perfil de deficiente fruto de um desamparo social.

Como a frequência à escola é obrigatória, a família é dada como incapaz e as crianças consideradas em situação de risco. Nestes casos - que não são raros - a negligência fica constatada, e as autoridades encaminham as crianças para o Centro de Atendimento Temporário. Feitas avaliações, 
as opções são: reintegrados à família, família de acolhimento ou adotados. Em Portugal, é muito comum mães afirmando "tirem-me um que faço outro". (Leonor, sala de apoio, especialista em educação especial do Agrupamento de Escolas Gonçalo Nunes, em Barcelos)

A professora ressalta que estes alunos, hoje "deficientes", não eram assim considerados na escola primária, o que torna a situação fácil de ser atribuída às condições sociais.

Se o serviço de apoio socioeducativo funcionasse, evitar-se-iam muitos casos de referenciados à educação especial. Ao retirarmos os meninos da sala regular, eles perdem oportunidades. Depende da funcionalidade deles, que tem relação com as funções do corpo, atividade, participação e fatores socioambientais. (Berta, coordenadora de ensino especial do Agrupamento de Escolas Gonçalo Nunes, em Barcelos)

No ideário da educação especial, a indicação, num primeiro momento, é incluir o aluno na sala regular, mas, dependendo da severidade da problemática, nem sempre é possível. A sala de apoio pedagógico e a unidade de multideficiências são espaços complementares no processo de escolarização.

A partir de um currículo específico, um dos alunos não faz Matemática nem Português na sala regular, mas cursa Formação Cívica e Educação Visual Tecnológica (trabalhos práticos como jardinagem e culinária) na sala de apoio. (Leonor, sala de apoio pedagógico, especialista em educação especial, Agrupamento de Escolas Gonçalo Nunes, em Barcelos)

Vinculadas à cultura da região do Minho, as atividades da sala de apoio envolvem a confecção de doces típicos, como sonhos (regados ao vinho do Porto), e os trabalhos com barro, considerando-se que há oleiros na região. Desde o início do semestre a sala vai sendo construída a partir das ações dos alunos em termos de adereços e decoração, como quadros e tapetes. Os PEI preveem atividades que respeitam o programa da turma regular e são adaptadas às caraterísticas de cada aluno na sala de apoio pedagógico. Norteados pela lógica da reciclagem, tapetes são produzidos com tecidos enviados pelas fábricas. Tomemos um depoimento sobre uma aluna com o diagnóstico de autismo grave:

De acordo com o seu PEI - que é flexível -, Jerusa frequenta apenas a sala de apoio pedagógico, em função de suas limitações de comunicação e interação. Sua produção é através de símbolos - pois não escreve, não fala e não lê -, por um caderno produzido exclusivamente para ela com imagens em que ela aponta o seu desejo, como desenhar, por exemplo. Ela evoluiu muito, pois quando chegou à escola era carregada e não olhava ninguém. Continua a não falar, mas suas possibilidades de interação e autonomia melhoraram muito. (Leonor, sala de apoio, especialista em educação especial, Agrupamento de Escolas Gonçalo Nunes, em Barcelos)

Segundo as professoras, no processo de inclusão se estimula a integração social, na medida em que muitos jovens com NEE - que não 
conseguem se alfabetizar - têm seus interesses considerados como de qualquer jovem, como namorar ou ir ao futebol. Foi ressaltado que, neste contexto, não interessa muito o acúmulo de conhecimento, mas sim reverter a condição social de persona non grata através de intervenções que estimulem o respeito ao outro. Ficou evidenciada a impropriedade de atitudes paternalistas com relação aos alunos adolescentes, considerando-se que muitos são tratados como "os inhos": Renanzinho, Paulinho, etc.

Em 2006, o Ministério da Educação criou os quadros de educação especial, exigindo formação especializada e supervisão em termos materiais e técnicos. A prevalência de alunos com NEE de $2 \%$ em Barcellos é superior à taxa nacional, de 1,8\%, em função da escola ser uma referência.

Uma questão significativa refere-se ao critério para elegibilidade. Muitos alunos referenciados não entraram em educação especial, mas precisavam de apoio educativo, que deve funcionar como uma prática preventiva para educação especial. Segundo a professora Berta, a educação especial é dirigida para alunos deficientes ou com baixa funcionalidade:

A funcionalidade é a possibilidade de o aluno conseguir estar num ambiente de aprendizagem de forma a dar respostas; a capacidade de aprendizagem em diferentes níveis tem relação com as limitações orgânicas e com a participação. Em Portugal há um hiato: ou está na educação especial ou não está em nada. (Berta, coordenadora de ensino especial do Concelho de Barcelos)

Outro espaço pedagógico refere-se à sala de multideficiência, voltada para alunos com graves deficiências ou com problemas de socialização. Terapia ocupacional, musicoterapia e terapia da fala são as especialidades de apoio à multideficiência. Com a alternância de ambientes entre a sala de multideficiência e a sala regular, alunos com NEE - considerados casos graves quanto a aspectos cognitivos, interação e socialização - da escola de Ponte da Barca recebiam apoio de professoras de educação especial, fisioterapeutas, auxiliares de ações educativas e musicoterapeuta.

A Escola da Ponte, em Vila das Aves - reconhecida pelo seu projeto educativo pouco tradicional -, está organizada segundo a lógica de projeto e de equipe. Suas práticas são alicerçadas nos seguintes princípios:

1) efetiva diversificação das aprendizagens, tendo por referência uma política de direitos humanos;

2) igualdade de oportunidades e realização de todos;

3) promover nos processos formativos uma solidariedade ativa.

O projeto acentua que as necessidades de cada educando devem ser atendidas singularmente, já que cada aluno tem sua própria forma de apreensão da realidade. 
Consideramos que todos os alunos têm necessidades especiais. Mas há uns que são mais especiais ainda. Estes estão nos grupos como qualquer um, e a primeira ajuda vem do grupo de colegas. Para além disso, temos especialistas em educação especial que organizam materiais tendo em conta as necessidades específicas de cada um. (Ana Moreira, coordenadora de projetos da Escola da Ponte, em Vila das Aves)

\section{Plano Individual de Transição (PIT)}

Qualquer adolescente que esteja a terminar a sua vida escolar se coloca o problema do ingresso no mundo do trabalho (Correia, 2008a).

Na escola de Vila Praia de Âncora, o Modelo de Atendimento à Diversidade (MAD) está sendo posto em prática numa experiência estimulante do ponto de vista pedagógico e político. Em uma visita, observamos a sala de aula regular de $6^{\circ}$ ano, na qual havia quatro alunos com NEE. Era evidente a preocupação da professora com a participação dos alunos com NEE e seus ritmos de aprendizagem. Nos Planos Educativos Individualizados (PEI) eram ressaltadas as necessidades e competências dos alunos, as intervenções coletivas e as singularizadas em grupos pequenos. Dois deles acompanhavam o currículo da turma regular com apoio da professora de educação especial. Os outros, por já serem mais velhos, terem retenções e não apresentarem competência matemática para acompanhar o currículo, frequentavam aulas de matemática funcional, de acordo com o seu Plano Individual de Transição. Nesse espaço pedagógico visava-se o incremento da funcionalidade do aluno e o enfrentamento do acesso à vida ativa. Considerando que uma das suas dificuldades era lidar com dinheiro, Alex era orientado a desenvolver atividades como fazer compras, pagamentos e depósitos no Multibanco, através das quais exercitava operações simples. O Plano Individual de Transição é focado em alunos com NEE já no final do ensino fundamental, com cerca de 15 anos, e prevê atividades que possam prepará-los para o mundo profissional.

Em equipe formada por pais, alunos, professores e orientadores, decidiu-se, a partir dos seus interesses e capacidades, as áreas nas quais poderiam atuar. Kátia pretendia ser policial de investigação criminal, e verificou-se que este papel exigia um nível de capacidades além do que ela tinha. Neste caso, outras possibilidades profissionais foram consideradas, como treinadora de cães. (Rosa Maria Ferreira, coordenadora de educação especial da escola de Vila Praia de Âncora)

Consideremos o relato da professora de matemática funcional:

Precisamos prepará-los para a vida ativa. Muitos têm dificuldades porque não receberam ajuda. Alex é habilidoso e dedicado, embora não seja criativo e tomar decisões seja problemático para ele. Pensamos na jardinagem, pois é uma área estimulada na região. 
A importância da lei no que se refere ao Plano Individual de Transição (PIT) foi ressaltada:

A lei do PIT é recente e nesta escola já está sendo posta em prática, o que é incomum em Portugal. Existe a lei, mas o sistema ainda não está preparado. Uma escola para atender às necessidades desses alunos deve ter um modelo como base prevendo professores de matemática funcional, educação para cidadania ou português para a vida. É uma política educacional interna da escola. (Rosa Maria Ferreira, coordenadora de educação especial da escola de Vila Praia de Âncora)

A partir de um investimento em conjunto da escola e das famílias, é preciso transformar o tempo de formação de modo a garantir autonomia e realização social dos alunos com NEE (Correia, 2008b). Uma estratégia de apoio aos alunos com NEE dentro do PIT refere-se à disciplina Educação para Cidadania, na qual se enfatizam questões do cotidiano na escola de Vila Praia de Âncora. Vale registrar que esta aula, num pequeno grupo, é planejada individualmente, porém contextualizada ao currículo da sala regular. Considerando que a comunidade da escola frequentava a piscina pública, alunos sob a orientação das professoras de Educação Especial e de Língua Portuguesa construíram um folheto de alerta à comunidade, com orientações sobre o "pé de atleta" (micose), seus sintomas e o comportamento preventivo. Vale ressaltar que tanto o texto como as imagens do folheto foram produzidos pelos alunos. Esta experiência reflete uma aprendizagem articulada ao contexto da comunidade na qual a escola está integrada. Numa outra experiência de aula, cujo tema eram os símbolos do Natal, decidiu-se produzir cartões que saíssem do lugar comum, e cada aluno foi responsável pela elaboração de um cartão. Em um dos lados do cartão havia o símbolo, seu significado e origem, e, no outro, uma mensagem pragmática sobre segurança, como, por exemplo, o perigo de a vela vir a provocar incêndio. A obesidade - pelo fato de nesta fase do ano se comer demasiadamente - e a questão do excesso de bebidas foram igualmente tematizadas.

O planejamento das atividades é realizado pelos alunos de acordo com os seus interesses, visando valorizá-los. É importante que utilizem estes conhecimentos nas suas vidas. As atividades estão articuladas com os projetos da escola e centradas nas experiências deles. (Professora de Educação para Cidadania da escola de Vila Praia de Âncora)

Com relação ao PIT, o Agrupamento de Escolas Gonçalo Nunes mantém um protocolo com uma instituição na qual alunos, a partir do $7^{\circ}$ ano de escolaridade, recebem um aprendizado profissional. O processo tem um caráter transicional, porque os alunos frequentam concomitantemente a escola e a instituição de formação profissional. Normalmente, vão para a horta ou para a cozinha aprender a fazer doces. Como o artesanato é rico na região, estas atividades eram muito exploradas (O galinho típico de Barcelos - um dos símbolos de Portugal - estava representado em uma tapeçaria produzida por uma das alunas). Ao perguntarmos aos alunos sobre os doces típicos da região, todos os nomearam: Pudim Abade 
de Priscos, Sonhos, Pasteis de Nata (ou Pasteis de Belém), Rabanadas, Churros e Fartura. As professoras ressaltaram que, apesar das limitações cognitivas, a maioria dos alunos é muito funcional, e, por vezes, isso passa despercebido. Ficou evidenciada a necessidade de sensibilizar os professores no sentido de não valorizarem apenas conhecimentos formais e científicos.

As políticas se voltam para a massa, mas educação especial não pode ser em massa. Não é incomum professores lidarem com adolescentes com atividades descontextualizadas e infantilizadoras. (Berta, coordenadora de educação especial no Agrupamento de Escolas Gonçalo Nunes)

Convênios com outras instituições são fundamentais para o PIT. O Agrupamento de Escolas de Ponte da Barca, visando a preparação profissional dos alunos com NEE, tem protocolo com a Associação Portuguesa de Pais e Amigos do Deficiente Mental (APPADM) e com o Centro de Atividades Ocupacionais.

Carina, com o Espectro do Autismo num grau elevado, está no $5^{\circ}$ ano, frequenta a sala de multideficiência e desenvolve a habilidade de copeira aqui mesmo no refeitório da escola. Muitos - por suas limitações - não têm condições de serem encaminhados para o mundo do trabalho, mas realizam atividades condizentes com as de um adulto na escola. (Inácia Ramos, professora de educação especial do Agrupamento de Escolas de Ponte da Barca)

A aprendizagem na educação especial deve trabalhar competências como psicomotricidade de forma significativa e contextualizada, considerando os interesses de vida do adolescente, evitando infantilizá-los.

Temos meninos que sabem sobre uma série da televisão, usam internet e palavras em inglês que não sabem nem em português. Víamos jovens fazendo viamentos que são atividades infantis, assim é melhor ajudar na copa classificando talheres, que já envolve uma atividade mental. Uma jovem precisava de uma matemática prática e foi orientada a trabalhar na cantina, com sucesso. Temos casos de alunos com Síndrome de Down trabalhando na lavagem de carro e em pizzarias. (Berta, coordenadora de ensino especial no Agrupamento de Escolas Gonçalo Nunes, em Barcelos)

O maior indicador de integração social de alunos com NEE refere-se à empregabilidade. Um estudo longitudinal britânico examinou a qualidade de vida, em termos de status de emprego, independência e vida social, de ex-alunos com dificuldade de aprendizagem - transferidos de uma escola especial para uma inclusiva, nove anos após deixarem a escola (Hornby, Kidd, 2001). Havia um percentual significativo de pais e alunos satisfeitos com a transferência; entretanto, a maior satisfação se dava entre os alunos transferidos para unidades especiais na escola do que entre aqueles que frequentavam as turmas regulares. O estudo revelou um baixo nível de qualidade de vida entre os ex-alunos, com altas taxas de vida social pobre, com escassa independência. Constatou-se que 
havia maior capacidade para conseguir emprego entre os ex-alunos que receberam um treinamento profissional na escola do que entre aqueles que não o haviam recebido. Por fim, destacou-se a importância de um currículo mais funcional relativo ao mundo do trabalho e às orientações vocacionais para alunos com dificuldade de aprendizagem moderada.

\section{O projeto Cognição em Movimento ${ }^{4}$}

No Brasil, a Constituição Federal de 1988 estabelece no art. 206 que o ensino seja ministrado com base no princípio da igualdade de condições para o acesso e permanência na escola, e, no art. 208, "O dever do Estado com a Educação será efetivado mediante a garantia de: [...] III - atendimento educacional especializado aos portadores de deficiência, preferencialmente na rede regular de ensino". Nessa perspectiva, o projeto Cognição em Movimento analisou o impacto dos jogos educativos eletrônicos como instrumento de avaliação interativa no desenvolvimento cognitivo de alunos com NEE em uma escola pública no Rio de Janeiro. O recorte teórico fundou-se na inclusão concebida como um fenômeno sócio-histórico e no conceito de zona de desenvolvimento proximal (Vygotsky, 2003). Considerou-se que a inclusão escolar demanda tanto um apoio psicopedagógico singularizado quanto a construção de práticas coletivas que garantam o desenvolvimento integral de alunos com NEE (Coelho, 2011). Uma intervenção psicopedagógica através de jogos eletrônicos educativos (GCompris), envolvendo dimensões cognitivas lógicas, matemáticas e espaciais, foi desenvolvida em alunos com déficits cognitivos. No mundo contemporâneo, a cultura de mídia tomou o lugar das instituições tradicionais como instrumento de socialização e desenvolvimento. Assim, jovens recebem, através das corporações de mídia, elementos formadores de identidade (Kellner, 2008). O jogo eletrônico - como prática lúdica da cultura contemporânea - pode ser considerado um instrumento de intervenção no processo de ensinoaprendizagem e de inclusão social de classes pobres, na medida em que a classe média já vive no seu cotidiano experiências com o uso da tecnologia. Assim, o ambiente escolar pode se beneficiar do poder da cultura midiática, sustentando o lugar social e o potencial de aprendizagem de alunos com NEE.

Considerando que o psicodiagnóstico de alunos com NEE se mostra controverso na medida em que se corre o risco de rotulações, enfatizando-se o aspecto patológico, a "avaliação interativa" foi considerada uma abordagem prescritiva a esta população ao focar a responsividade do aprendiz. Assim, destacam-se as possibilidades de aprendizagem dos alunos através de uma avaliação sistêmica, interativa e contextualizada, visando modificar o funcionamento cognitivo através da assistência de um mediador. Baseada na teoria da modificabilidade estrutural cognitiva (SCM) de Feuerstein e pela experiência da aprendizagem mediada (Haywood, Tzuriel, 1992), a avaliação interativa tem como hipótese a capacidade 
do ser humano de modificar suas funções cognitivas e adaptar-se às demandas das situações de vida. A modificabilidade envolve um processo interacional, no qual professores se interpõem entre os alunos e a realidade, modificando o set de estímulos, sua frequência, intensidade e contexto. Mediadores aumentam a vigilância e a sensibilidade do aprendente, criando relações de causa e efeito, temporais e espaciais entre os estímulos. Haywood e Tzuriel (1992) sugeriram características necessárias à interação, a saber:

a) intencionalidade e reciprocidade, produzindo no aluno sentimentos de competência e autodeterminação;

b) mediação do significado pelo aspecto afetivo-motivacional;

c) a possibilidade de transcender a necessidade imediata da situação para outros objetivos. Implicado com o processo, o mediador mostra-se flexível, explora o significado dos fracassos através de feedback.

Neste paradigma, os aspectos afetivo-emocionais ativam as habilidades metacognitivas. Os sujeitos da pesquisa foram 15 alunos com NEE, de 7 a 14 anos, do ensino fundamental, em uma região considerada em desvantagem social. Os alunos foram submetidos à avaliação cognitiva (WISC-III) tradicional, visando especificar o nível intelectual de cada um. Após um treinamento, foi realizado o pré-teste, no qual foram aplicadas as atividades do GCompris sem ajuda do aplicador. O GCompris é um jogo eletrônico educativo, com atividades de matemática (chapéu-mágico e jogo da balança), atividades visoespaciais (Tangram e Torre de Hanói) e uma de lógica que envolve um jogo de estratégias (Lig 4). Após os pré-testes, realizou-se uma intervenção com os mesmos jogos nos pressupostos da avaliação interativa. No design da pesquisa, o sujeito funciona como seu próprio controle, com medidas antes e após a mediação. Por fim, realizou-se o pós-teste, no qual se aplicou novamente o GCompris sem intervenção do aplicador, para verificar o efeito da mediação e a extensão pelos quais os sujeitos aprenderam conceitos e estratégias de solução de problemas.

A intervenção baseada na Avaliação Interativa valorizou os aspectos motivacionais e afetivo-emocionais do desempenho. O programa GCompris foi aplicado três vezes por semana, com tempo médio de 90 minutos, por quatro meses. Na fase de assistência, o avaliador visa o desempenho potencial do aluno, fornecendo pistas, instruções passo a passo, demonstração, feedback sistemático, reforço com técnicas como ábaco para matemática e estímulo à autorregulação. Já na fase de manutenção suspende-se a ajuda, a fim de saber se as estratégias de raciocínio se mantêm. A organização espacial da turma - com alunos dispostos em duplas, diferentemente da linearidade tradicional - contribuiu para um clima de entusiasmo e questionamento (Dockrell, McShane, 2000). A avaliação cognitiva no WISC-III revelou uma amostra homogênea de alunos classificados como deficientes cognitivos ou 
limítrofes, com diferenças nos perfis nos subtestes. Observações das professoras indicaram o perfil do grupo com menor interesse e motivação para atividades de leitura e escrita.

Visando analisar o efeito da intervenção baseada na avaliação interativa, verificou-se a significância da diferença entre os resultados do pré e pós-teste através do teste não-paramétrico de Postos com Sinal Wilcoxon para dados emparelhados produzidos antes e depois da intervenção. O teste mostrou um aumento significativo nos escores dos jogos de Matemática $1(\mathrm{Z}=2,95, \mathrm{p}<0,01)$, Matemática $2(\mathrm{Z}=2,95$, $\mathrm{p}<0,01)$, Matemática $4(\mathrm{Z}=2,43, \mathrm{p}<0,01)$, Torre de Hanói $(\mathrm{Z}=$ 2,99, p < 0,01) e Lógica ( $Z=2,46, p<0,01)$, com exceção dos testes Matemática 3 e o Tangram, cujas diferenças não foram significativas. Os dados foram analisados através do Statistical Package for Social Science (SPSS 17.0). A diferença estatística significativa entre as médias dos prétestes e pós-testes nos levou a admitir que a abordagem da avaliação interativa contribuiu para a plasticidade cognitiva, a transcendência da aprendizagem, a autorregulação e a mediação de sentimentos de competência entre os alunos. Foram levantados os significados que a tecnologia na educação assume nos processos de subjetivação e de inclusão social no mundo contemporâneo.

A utilização de perspectivas - a tradicional e a interativa, com distintos pressupostos teóricos - permitiu compreender melhor o aluno, na medida em que cada tipo de avaliação considera diferentes aspectos do desempenho: o produto da aprendizagem, no caso da avaliação tradicional, e o processo, na avaliação interativa. Tomando como referência o conceito de desenvolvimento proximal, foi possível avaliar o nível do desenvolvimento real do aluno comparado ao de seus pares, bem como identificar o seu potencial, ou seja, seu modo de funcionamento cognitivo sob ajuda.

A diferença não significativa entre o pré-teste e o pós-teste na atividade do Tangram - que se assemelha a um quebra-cabeça - pode ser compreendida por se tratar de uma habilidade mais primitiva que os alunos já dominavam, embora sempre demonstrassem motivação em executá-las. Já na atividade 3 de matemática (subtração), na qual as diferenças entre os pré-testes e pós-testes igualmente não foram significativas, se devem à complexidade da tarefa acima do alcance dos alunos. A suscetibilidade de alunos com déficits cognitivos à intervenção psicopedagógica baseada nos princípios da inclusão social funciona de modo positivo (Enumo, 2004), mormente quando há interação desses alunos com pares diferentes, contribuindo para a diminuição de preconceitos e de condições sociais estigmatizantes. Contudo, é preciso considerar que, além das habilidades sociais, as necessidades como as competências cognitivas demandam uma intervenção singularizada. Em suma, evidenciou-se a adequação da avaliação interativa no cenário da inclusão, com destaque para as dimensões afetivo-emocionais e mediacionais, e do uso da tecnologia na construção de competências para o processo ensino-aprendizagem. 


\section{Considerações finais}

Na análise do contexto português, os dados nos levaram a admitir que havia muitas vezes um gap significativo entre os modelos teóricos dominantes, os discursos acerca do processo e as intervenções efetivamente adotadas, com variações nas experiências em diferentes escolas, ainda que mantidos os princípios da política de inclusão. Contudo, vale lembrar que a amostra utilizada é restrita e não representativa, o que nos impede de fazer generalizações acerca da realidade nacional de Portugal. O acompanhamento do desenvolvimento dos alunos com NEE fez perceber uma indissociabilidade entre as relações que estabelecem nos sistemas microssociais e as condições macrosistêmicas - como as políticas públicas -, assim como as características culturais do meio. A validade ecológica da pesquisa teve como ponto forte o estudo sobre o desenvolvimento do sujeito com NEE, considerando os ambientes reais, suas vicissitudes como contextos desenvolvimentais, identificadas as características individuais, as estruturas interpessoais e as estruturas sociais de apoio.

A pesquisa brasileira foi realizada lançando mão de atividades levadas a efeito no cotidiano da própria escola e integrada ao planejamento pedagógico, nos pressupostos da Lei Federal, caracterizando-se como uma perspectiva ecológica.

Evidenciou-se no trabalho o princípio da precocidade, a partir do qual se entende que, quanto mais cedo diagnosticarmos e atuarmos sobre as necessidades e quanto mais cedo alunos com NEE interagirem com outros sem problemas, em contextos potencialmente estimulantes e com o apoio de profissionais, maiores serão suas possibilidades de desenvolvimento.

Podemos admitir que as intervenções observadas nas escolas portuguesas - ainda que muito heterogêneas - são exitosas no que se refere à inclusão dos alunos com NEE por estarem articuladas com o contexto mais amplo a que pertencem e potencializarem o desenvolvimento dos alunos. A construção de Planos Educacionais Individualizados de cada aluno com NEE articulada aos projetos curriculares da escola constitui um bom exemplo de uma experiência alinhada a uma filosofia inclusiva. Os Planos Individuais de Transição desenvolvidos nas escolas do contexto português tentam efetivamente concretizar uma articulação das necessidades, competências e interesses do aluno com as tradições culturais das regiões norteados por um modelo de inclusão. O trabalho em equipe - tanto na realidade brasileira quanto na portuguesa - refletiu um dos aspectos importantes da perspectiva contemporânea da inclusão, deslocando a atenção aos alunos com NEE de uma perspectiva médicoclínica para uma perspectiva sistêmica, interdisciplinar e, sobretudo, psicopedagógica.

Um ponto significativo da pesquisa referiu-se ao fato de os alunos com DAE - tanto em Portugal quanto no Brasil - ainda não terem seus direitos legais assegurados para serem elegíveis para educação especial. Embora não tivessem o apoio da lei para receber os serviços de educação especial, 
as professoras, de uma forma responsável, ainda assim se prontificavam a desenvolver ações pedagógicas através de planejamentos estruturados. As experiências exitosas relatadas com estes grupos de alunos são iniciativas pontuais que refletem uma política interna das escolas. A questão econômica é certamente o motivo desta exclusão. Em Portugal, os direitos dos alunos com DAE são restringidos apenas a apoios educativos. Como bem nos informa a coordenadora de educação especial de Vila Praia de Âncora, "os alunos com DAE são os que mais precisam, pois são inteligentes, e sem o apoio especializado para se desenvolverem terão seus lugares garantidos na marginalidade e na exclusão". Finalizando, tomemos as palavras de Kron (2008, p. 12) referindo-se aos serviços de apoio ao aluno com NEE: "Um trabalho competente não depende apenas da boa vontade, mas também das possibilidades de formação individual e em equipe e da cooperação existente intraequipe e interequipe com os apoios externos especializados."

\section{Referências bibliográficas}

BRONFENBRENNER, Urie. A ecologia do desenvolvimento humano: experimentos naturais e planejados. Porto Alegre: Artes Médicas, 2002.

CARVALHO, R. E. Educação inclusiva: com os pingos nos is. Porto Alegre: Mediação, 2004.

COELHO, C. L. Intervenções psicopedagógicas via jogos eletrônicos no cenário da inclusão. Revista Galego-Portuguesa de Psicoloxía e Educacion, v. 19, n. 2, p. 183-195, 2011.

COLL, C.; MARCHESI, A.; PALACIOS, J. (Org.). Desenvolvimento psicológico e educação. Porto Alegre: Artmed, 2004. v. 3: Necessidades educativas especiais e aprendizagem escolar.

CORREIA, L. M. Inclusão e necessidades educativas especiais: um guia para educadores e professores. Porto: Porto Editora, 2008a.

CORREIA, L. M. Dificuldades de aprendizagem específicas: contributos para uma definição portuguesa. Porto: Porto Editora, 2008b.

CORREIA, L. M.; LAVRADOR, R. A utilidade da CIF em educação: um estudo exploratório. Braga: EE/DPEEE, Universidade do Minho, 2010.

CORREIA, L. M.; SERRANO, A. Inclusão e intervenção precoce: para um começo educacional promissor. In: CORREIA, L. M. Inclusão e necessidades educativas especiais: um guia para educadores e professores. Porto: Porto Editora, 2008. 
DOCKRELL, J.; MCSHANE, J. Crianças com dificuldades de aprendizagem: uma abordagem cognitiva. Porto Alegre: Artmed, 2000.

DUNST, C. J. Rethinking early intervention. Analysis and Intervention in Developmental Disabilities, v. 5, n. 1/2, p. 165-201, 1985.

. Revisiting "Rethinking early intervention". Topics in Early

Childhood Special Education, v. 20, n. 2, p. 95-104, 2000.

DUNST, C. J.; TRIVETTE, C. M.; DEAL, A. G. Enabling and empowering families: principles and guidelines for practice. Cambridge, MA: Brookline Books, 1998.

DUNST. C. J.; BRUDER, M. B. Family and community activity setting, natural learning enviroments, and children's learning opportunities. Children's Learning Opportunities Report, v. 1, n. 2, 1999.

ENUMO, S. Avaliação assistida para crianças com necessidades educacionais especiais: recurso auxiliar na inclusão escolar. Revista Brasileira de Educação, v. 11, n. 3, p. 335-354, 2004.

GLAT, R.; FERNANDES, E. M. Da educação segregada à educação inclusiva: uma breve reflexão sobre os paradigmas educacionais no contexto da educação especial brasileira. Inclusão, Revista da Educação Especial, Brasília, v. 1, n. 1, p. 35-39, out. 2005.

HAYWOOD, H.; TZURIEL, D. Interactive assessment. New York: Springer-Verlag, 1992.

HORNBY, G; KIDD, R. Transfer from special to mainstream - ten years later. British Journal of Special Education, v. 28, n. 1, p. 10-17, 2001.

KELLNER, D. Globalization and media spectacle: from 9/11 to the Iraq war. Revista Famecos: Mídia, Cultura e Tecnologia, Porto Alegre, v. 1, n. 35, 2008. Acesso em: $1^{\circ}$ de maio de 2010. Disponível em: $<$ http://www.revistas.univerciencia.org/index.php/famecos/article/ view/5361/4880>.

KRON, M. (Ed.) Early childhood education in inclusive setting: basis, background and Framework of inclusive early education in five European countries. Siegen: Univesrität Siegen, 2008. (ZPE Schriftenreihe Nr 20).

MACWILLIAN, R. A. It's only natural... to have early intervention in the environments where it's needed. In: SANDALL, S.; OSTROSKY, M. (Ed.). Young exceptional children. Denver, CO: Division for Early Childhood of the Council for Exceptional Children, 2000. v. 2 , p. 17-26. 
MEISELS, S. J.; ANASTASIOW, N J. The risks of predictions: relationships between etiology, handicapping conditions and developmental outcomes. In: MOORE, S. G.; COOPER, C. R. (Ed.). The young child: reviews of research. Washington, DC: National Association for Education of Young Children, 1982. v. 3, p. 259-280.

SERRANO, A. M. Redes sociais de apoio e sua relevância para a intervenção precoce. Porto: Porto Editora, 2008.

SERRANO, A. M.; AFONSO, J. L. Educação pré-escolar em contextos inclusivos: reflexões em torno de uma experiência européia Comenius. Inclusão, Revista da Educação Especial, Brasília, n. 10, p. 7-28, 2010.

VYGOTSKY, L. A formação social da mente. Porte Alegre: Artes Médicas, 2003.

Cristina Lucia Maia Coelho, doutora em Psicologia pela Universidade Federal do Rio de Janeiro (UFRJ), é professora associada de Psicologia da Educação da Faculdade de Educação da Universidade Federal Fluminense (UFF).

crismaia84@gmail.com

Recebido em 28 de março de 2012.

Aprovado em 7 de novembro de 2012. 